\title{
Bidirectional Regulation of Amyloid Precursor Protein- Induced Memory Defects by Nebula/DSCR1: A Protein Upregulated in Alzheimer's Disease and Down Syndrome
}

\author{
Jillian L. Shaw, ${ }^{1,2}$ Shixing Zhang, ${ }^{1}$ and Karen T. Chang ${ }^{1,2,3}$ \\ 'Zilkha Neurogenetic Institute, ${ }^{2}$ Neuroscience Graduate Program, and ${ }^{3}$ Department of Cell and Neurobiology, Keck School of Medicine, University of \\ Southern California, Los Angeles, California 90089
}

\begin{abstract}
Aging individuals with Down syndrome (DS) have an increased risk of developing Alzheimer's disease (AD), a neurodegenerative disorder characterized by impaired memory. Memory problems in both DS and AD individuals usually develop slowly and progressively get worse with age, but the cause of this age-dependent memory impairment is not well understood. This study examines the functional interactions between Down syndrome critical region 1 (DSCR1) and amyloid-precursor protein (APP), proteins upregulated in both DS and $\mathrm{AD}$, in regulating memory. Using Drosophila as a model, we find that overexpression of nebula (fly homolog of DSCR1) initially protects against APP-induced memory defects by correcting calcineurin and cAMP signaling pathways but accelerates the rate of memory loss and exacerbates mitochondrial dysfunction in older animals. We report that transient upregulation of Nebula/DSCR1 or acute pharmacological inhibition of calcineurin in aged flies protected against APP-induced memory loss. Our data suggest that calcineurin dyshomeostasis underlies age-dependent memory impairments and further imply that chronic Nebula/DSCR1 upregulation may contribute to age-dependent memory impairments in AD in DS.
\end{abstract}

Key words: alzheimer's disease; calcineurin; Down syndrome; DSCR1; memory; Nebula

Significance Statement

Most Down syndrome (DS) individuals eventually develop Alzheimer's disease (AD)-like dementia, but mechanisms underlying this age-dependent memory impairment remain poorly understood. This study examines Nebula/Down syndrome critical region 1 (DSCR1) and amyloid-precursor protein (APP), proteins upregulated in both DS and AD, in regulating memory. We uncover a previously unidentified role for Nebula/DSCR1 in modulating APP-induced memory defects during aging. We show that upregulation of Nebula/DSCR1, an inhibitor of calcineurin, rescues APP-induced memory defects in young flies but enhances memory loss of older flies. Excitingly, transient Nebula/DSCR1 overexpression or calcineurin inhibition in aged flies ameliorates APPmediated memory problems. These results suggest that chronic Nebula/DSCR1 upregulation may contribute to age-dependent memory loss in $\mathrm{DS}$ and $\mathrm{AD}$ and points to correcting calcineurin signaling as a means to improve memory during aging.

\section{Introduction}

Down syndrome (DS), due to full or partial triplication of chromosome 21, greatly increases the risk of Alzheimer's disease (AD). By age $65, \sim 75 \%$ of DS individuals will develop dementia as compared to $13 \%$ of age-matched controls (Bush and Beail,

\footnotetext{
Received March 24, 2015; revised June 8, 2015; accepted July 8, 2015.

Author contributions: J.L.S., S.Z., and K.T.C. designed research; J.L.S. and S.Z. performed research; J.L.S., S.Z., and K.T.C. analyzed data; J.L.S. and K.T.C. wrote the paper.

This work was supported by National Institutes of Health Grant NS080946, the Jerome Lejeune Foundation, the Alzheimer's Association (K.T.C.), and Global Down Syndrome Foundation (K.T.C.).

The authors declare no competing financial interests.

Correspondence should be addressed to K. T. Chang, 1501 San Pablo Street, Zilkha Neurogenetic Institute 235, Los Angeles, CA 90089-2821. E-mail: changkt@usc.edu.

DOI:10.1523/JNEUROSCI.1163-15.2015

Copyright $\odot 2015$ the authors $\quad 0270-6474 / 15 / 3511374-10 \$ 15.00 / 0$
}

2004). Despite an early presence of the neurochemical changes seen in AD brains (Leverenz and Raskind, 1998; Head et al., 2001; Perluigi et al., 2014), dementia is delayed in most DS individuals until after mid-life, suggesting both a genetic risk for dementia and the existence of a neuroprotective period before the onset of memory impairments. The mechanism underlying this agedependent memory decline is poorly understood, but the well known connection between $\mathrm{DS}$ and $\mathrm{AD}$ provides a unique opportunity to identify common genetic factors contributing to $\mathrm{AD}$ and age-associated dementia.

To uncover mechanisms underlying age-dependent memory decline in $\mathrm{AD}$ and $\mathrm{DS}$, we examined the functional interactions between two genes encoded by chromosome 21 and upregulated in both $\mathrm{DS}$ and $\mathrm{AD}$. The amyloid precursor protein $(A p p)$, en- 
coded by chromosome 21, is a known risk gene for $\mathrm{AD}$ because either mutations or duplication of App is associated with familial AD (Chartier-Harlin et al., 1991; Goate et al., 1991; Murrell et al., 1991; Rovelet-Lecrux et al., 2006; Sleegers et al., 2006; Kasuga et al., 2009). Studies have shown that overexpression of the wildtype human APP in both mouse and Drosophila causes cognitive deficits before $\beta$-amyloid accumulation (Greeve et al., 2004; Simón et al., 2009; Chakraborty et al., 2011), suggesting that APP perturbation could contribute to dementia independent of $\beta$-amyloid plaques. Another gene encoded by chromosome 21 that is likely to play a crucial role in $\mathrm{AD}$ is the Down syndrome critical region 1 (Dscr1; also known as Rcan-1) gene. Postmortem brains from both DS and AD patients show an upregulation of DSCR1 mRNA and protein levels (Cook et al., 2005; Sun et al., 2011). Oxidative stress, APP upregulation, and $\beta$-amyloid exposure have also been shown to induce DSCR1 upregulation (Ermak et al., 2002; Lloret et al., 2011; Wu et al., 2015). DSCR1 encodes an evolutionarily conserved inhibitor of calcineurin, a serine/threonine calcium/calmodulin phosphatase important for numerous physiological pathways, including memory, cell death, and immunity (Fuentes et al., 1995, 2000; Aramburu et al., 2000). Studies have shown that altering levels of DSCR1 in mouse and Nebula (fly homolog of DSCR1) in Drosophila severely impaired memory (Chang et al., 2003; Hoeffer et al., 2007; Dierssen et al., 2011; Martin et al., 2012). However, upregulation of Nebula/ DSCR1 has been shown to both promote and inhibit cell survival after oxidative stress (Ermak et al., 2002; Porta et al., 2007; Sun et al., 2011, 2014), as well as protect against APP-induced neurodegeneration and axonal transport defects (Shaw and Chang, 2013). Thus, it remains unknown how Nebula/DSCR1 upregulation will affect APP-induced memory defects.

Drosophila and humans share conserved cell signaling components and pathways essential for learning and memory formation (Dubnau and Tully, 1998; Davis, 2011), thus providing an effective model system for studying mechanisms contributing to age-dependent memory impairments and neurological disorders. Drosophila has also been used successfully as a model system to investigate mechanisms underlying various neurological disorders (Warrick et al., 1998; Feany and Bender, 2000; Steffan et al., 2001; Jackson et al., 2002; Chen et al., 2003; Yang et al., 2003; Iijima et al., 2004; Clark et al., 2006; Carmine-Simmen et al., 2009; Iijima-Ando and Iijima, 2010; Lu and Vogel, 2009; Guo, 2010; Sofola et al., 2010). Using Drosophila, here we show that overexpression of nebula rescued memory impairments induced by APP upregulation through inhibition of calcineurin. These protective effects did not persist during aging, and Nebula coupregulation instead accelerated age-dependent memory impairments, increased reactive oxygen species (ROS), and enhanced mitochondrial dysfunctions in aged flies. Furthermore, we demonstrate that transient upregulation of Nebula or acute pharmacological inhibition of calcineurin in aged flies was sufficient to restore APP-induced memory loss. These findings suggest that Nebula/DSCR1 upregulation may contribute to progressive dementia by initially rescuing APP-induced memory loss but accelerating the rate of memory impairment in older animals.

\section{Materials and Methods}

D. melanogaster stocks and material. Flies were cultured at $25^{\circ}$ on standard cornmeal, yeast, sugar, and agar medium under a $12 \mathrm{~h} \mathrm{light/dark}$ cycle. The following fly lines were obtained from the Bloomington Drosophila Stock Center: UAS-APP695-N-myc (6700), sgg $^{1} / F M 7 a$, UAS-nla-RNAi (27260), UAS-CaNB-RNAi (27307), and UAS-PKA-
C1.FLAG. The Elav-Gal4 stock was generously provided by Dr. Mel Feany (Harvard University, Boston, MA). The UAS-nla ${ }^{t 1}$ was reported on previously as was the C739-GAL4 driver (Chang et al., 2003). The mushroom body gene-switch flies were kindly provided by Dr. Gregg Roman (University of Houston, Houston, TX).

Pavlovian olfactory learning and memory assays. Drosophila aged 2-4, $7-10,30-33$, and $42-45 \mathrm{~d}$ were tested in the T-maze for the Pavlovian olfactory conditioning assay (Tully and Quinn, 1985). Before testing, the apparatus was humidified for $2 \mathrm{~h}$ with a vacuum connected to an air bubbler. 3-Octanol (OCT) and 4-methylcyclohexanol (MCH; SigmaAdrich) were diluted in mineral oil to $50 \%$. Tube lengths connecting the odor and the testing apparatus were adjusted to allow flies to distribute equally between OCT and $\mathrm{MCH}$. Groups of $\sim 50-100$ flies were trained with one odor $(\mathrm{MCH})$ that was paired with a shock $(60 \mathrm{~V})$. Subsequently, flies were given $60 \mathrm{~s}$ of exposure to a non-shock paired odor (OCT). Immediately after training, short-term memory (STM) was evaluated by giving the flies $2 \mathrm{~min}$ to distribute between the two odors. To test longterm memory (LTM), flies were subjected to the same training protocol but repeated for 10 training sessions with 15 min rest intervals between sessions. Flies were then tested immediately or $24 \mathrm{~h}$ after training. All training was performed under red light in the dark room. The performance index was calculated as the number of flies that avoided the unconditioned stimulus subtracted from the number of flies that avoided the conditioned stimulus (odor and electric shock). This value was multiplied by 100 and divided by the total number of flies. For sensorimotor tests, flies were habituated to the apparatus and given $2 \mathrm{~min}$ to choose between the arm with the aversive odor or air. This was repeated for electric shock and reported as the percentage of flies that avoided $\mathrm{MCH}$, OCT, and shock.

Protein kinase A activity assay. To evaluate protein kinase A (PKA) activity, fly extracts from Drosophila heads were prepared according to the conditions of the PepTag Assay for nonradioactive detection of cAMP-dependent protein kinase (Promega). Briefly, 10 heads/genotype were homogenized in $30 \mu \mathrm{l}$ of PKA extraction buffer and centrifuged, and $2 \mu \mathrm{l}$ from the supernatant was used for each genotype. The extracts from homogenized Drosophila heads were incubated in a $16 \mu \mathrm{l}$ reaction mixture with a fluorescent-tagged A1 peptide (PKA substrate), reaction buffer, and protease inhibitor for $30 \mathrm{~min}$. The reactivation was inactivated by heating at $95^{\circ} \mathrm{C}$ for $10 \mathrm{~min}$. The nonphosphorylated $\mathrm{A} 1$ peptide is +1 charged. After phosphorylation by active PKA in the samples, it switches to -1 charge. Using electrophoresis, the phosphorylated and nonphosphorylated forms can be separated on a $0.8 \%$ agarose gel. To visualize the fluorescent tag in the gel, a UV lamp was used and images were captured. Integrated density values were taken for phosphorylated and nonphosphorylated bands using NIH Image J. The relative PKA activity in each sample was calculated as the amount of phosphorylated Al peptide divided by the total Al peptide and normalized to values obtained for control flies.

Western blots. Drosophila adult heads were collected on dry ice and homogenized in cold RIPA buffer. Equal amounts of protein per genotype $(10-20 \mu \mathrm{g})$ was run on SDS polyacrylamide gel and transferred to a nitrocellulose membrane. Blocking for nonphosphorylated antibodies was done using 5\% milk in PBS-Tween 20 for $1 \mathrm{~h}$ at room temperature (RT). Blocking for phosphorylated antibodies was done using 5\% BSA in PBS-Tween 20. For detection of phosphorylated CREB, a nuclear extraction was performed using the NE-PER Nuclear and Cytoplasmic Extraction kit (Thermo Fisher Scientific). Membranes were incubated in the following antibodies overnight at $4^{\circ} \mathrm{C}$ : N-APP (1:2000; Sigma), $\beta$-tubulin (1:1000; Developmental Studies Hybridoma Bank), phosphorylated CREB (1:1000; Cell Signaling Technology), and TATA-BP (1:1000; Abcam). Secondary antibodies included anti-mouse and antirabbit HRP-coupled. HRP signals were detected using ECL Reagents (GE Healthcare). For reprobing, membranes were stripped using Reblot plus (Millipore). NIH Image J software was used to measure signal intensity. The fold change was then normalized to the loading control and compared with either control or APP flies.

Calcineurin activity. Fly heads were collected over dry ice and homogenized in lysis buffer (10 mM Tris, pH 7.4, 1 mm EDTA, 0.02\% sodium azide). Calcineurin phosphatase activity was determined using the Ser- 
ine/Threonine Phosphatase Assay kit (Promega) following the protocol of the manufacturer and as reported previously (Chang et al., 2003). Five micrograms of protein per genotype were used.

Immunohistochemistry. Adult Drosophila brains were dissected in PBS and fixed with $4 \%$ paraformaldehyde for $20 \mathrm{~min}$ at RT. Samples were blocked in 5\% normal goat serum in PBS plus $0.1 \%$ Triton X-100 for $1 \mathrm{~h}$ at RT and then incubated with primary antibodies overnight at $4^{\circ} \mathrm{C}$. The Fasciclin II (Developmental Studies Hybridoma Bank) antibody was used at 1:20. Alexa Fluor-conjugated secondary antibody was applied at 1:200, and whole-mount brains were mounted in Pro-Long Gold antifade reagent (Invitrogen). Z-stack images of the dissected brain were acquired using the LSM 5 microscope (Zeiss). Areas of the $\alpha$ and $\beta$ lobes of the mushroom bodies were measured using NIH Image J software. To minimize variability attributable to mounting and inherent differences between male and female brain size, the relative size of mushroom body was calculated by normalizing the area of the mushroom body containing $\alpha$ and $\beta$ lobes to the area of the central brain hemisphere taken at low magnification.

ATP abundance. ATP content was assayed using a colorimetric assay kit (BioVision) according to the protocol of the manufacturer. Briefly, Drosophila heads were collected on dry ice and homogenized in ATP assay buffer. Samples were deproteinated by centrifuging the extract for $1 \mathrm{~h}$ at $14,000 \mathrm{rpm}$ in $10 \mathrm{kDa}$ Vivaspin columns (Sartorius Stedim Biotech). Sample were incubated with reaction mixture and imaged with the microplate reader with an optical density of $570 \mathrm{~nm}$.

$R U 486$ transient induction. Flies that are either $2-4$ or $30-33 \mathrm{~d}$ were fed with or without $500 \mu \mathrm{M}$ RU486 (mifepristone) in $2 \%$ sucrose solution for $2 \mathrm{~d}$ before training and testing according to method described by Mao et al. (2004).

Pharmacological acute inhibition of calcineurin. Drosophila adults of 1 or $42 \mathrm{~d}$ were transferred to vials of food containing the calcineurin inhibitors cyclosporin A or FK506 (tacrolimus). Drugs were diluted and mixed in the food to a final concentration of $30 \mu \mathrm{M}$ cyclosporine A or FK506 for feeding for $3 \mathrm{~d}$. This concentration was selected because it effectively inhibited calcineurin to control levels with calcineurin activity assay after drug treatment. After feeding, Drosophila adults were tested on the pavlovian olfactory conditioning test, and heads were used for the calcineurin assay.

ROS detection. Flies were briefly etherized, and brains were dissected in Schneider's medium (Invitrogen). Freshly dissected fly brains were incubated with $20 \mu \mathrm{m}$ dihydroethidium (Invitrogen) at RT for $15 \mathrm{~min}$. After several washes in PBS, brains were mounted in Pro-Long Gold Antifade Medium (Invitrogen) between coverslips. To minimize variations in signal intensity, brains of different fly lines were mounted on the same slide, and fluorescence intensities of at least six brains were averaged.

Statistics. For multiple samples, ANOVA followed by Bonferroni's post hoc test was used to determine statistical significance. For paired samples, two-tailed Student's $t$ test was used. Samples were randomized during dissection, image collection, and data analyses to minimize bias.

\section{Results}

Nebula/DSCR1 upregulation protects against APP-induced memory impairments

To evaluate the effects of Nebula/DSCR1 upregulation in modulating APP-induced memory impairment, we measured STM in Drosophila using the classic pavlovian olfactory conditioning assay (Tully and Quinn, 1985). We assayed STM mainly because it is primarily impaired in the early stages of AD (Grady et al., 2001; Klekociuk and Summers, 2014). To bypass the locomotor defects caused by pan-neuronal APP overexpression (Shaw and Chang, 2013), we selectively upregulated APP and Nebula in the mushroom bodies, structures important for olfactory memory in Drosophila (Davis, 2011). This was done by generating transgenic flies containing UAS-APP $(A P P)$ with or without UAS-nebula $\left(n l a^{t 1}\right)$ under the control of C739-GAL4 driver. Consistent with previous reports, upregulation of either Nebula or APP alone caused severe STM defects (3 min memory) in young flies be- tween 2 and 4 d of age (Chang et al., 2003; Sarantseva et al., 2009), but co-upregulation of Nebula and APP surprisingly restored STM to normal (Fig. 1A). Western blot analyses and sensorimotor assays confirmed that preservation of STM in flies with APP and Nebula co-overexpression is not attributable to differences in APP transgene expression or changes in sensorimotor responses (Fig. 1B; Table 1). Reducing nebula expression using the UAS$n l a-R N A i(R N A i-n l a)$ transgene also resulted in STM defects alone, as well as when in the presence of APP overexpression. The UAS-nla-RNAi construct had been shown to effectively reduce Nebula protein levels by $>50 \%$ when expressed in neurons (Shaw and Chang, 2013) and caused STM defects similar to that reported for nebula mutant (Chang et al., 2003). Together, these results confirm that Nebula is important for normal STM and interacts genetically with APP to protect against APP-induced STM defects.

We next examined whether Nebula upregulation also effectively prevents LTM defects by assaying the performance index $24 \mathrm{~h}$ after 10-trial spaced training protocol (Tully et al., 1994). Figure $1 C$ shows that APP upregulation caused severe defects both immediately and $24 \mathrm{~h}$ after spaced training, indicating impaired memory acquisition and retention. Despite an initial decrease in performance index immediately after spaced training, flies overexpressing both APP and Nebula still performed well. In fact, when we normalized the performance index at $24 \mathrm{~h}$ after training to immediately after training, flies overexpressing APP and Nebula performed as well as control (control, $0.47 \pm 0.03$ vs APP and Nebula, $0.59 \pm 0.06 ; p=0.07$ ). These results indicate that Nebula upregulation also effectively protects against APPinduced LTM defects but further suggests that repeated training may trigger signaling pathways that feedback to affect the initial memory formation in APP and Nebula overexpressing flies.

\section{APP overexpression does not cause structural defects in the mushroom bodies}

Overexpression of APP in the mushroom bodies using the C739GAL4 driver caused severe memory defects in young flies; thus, we next examined whether abnormal mushroom body development underlies APP-induced memory problems. C739-GAL4 drives expression in the $\alpha$ and $\beta$ lobes of Drosophila mushroom bodies; therefore, we analyzed images of dissected brains stained with Fasciclin II, an antibody that can strongly stain the $\alpha$ and $\beta$ lobes of the mushroom bodies (Akalal et al., 2006). Fig. $1 D$ shows that the gross mushroom body structure was not altered across genotypes, suggesting that the memory deficit seen in flies with APP overexpression is not likely caused by defects in mushroom body development. This result is consistent with a report by Chakraborty et al. (2011) in which they showed that overexpression of APP using a pan-neuronal driver (Elav-GAL4) did not affect mushroom body structure.

\section{APP-mediated impairments in STM are rescued by restoring calcineurin or PKA activity}

Previous work has demonstrated that $A P P$ overexpression leads to calcineurin hyperactivation and subsequent GSK-3 $\beta$ activation, but nebula overexpression inhibits both perturbations through its ability to inhibit calcineurin (Shaw and Chang, 2013). Therefore, we tested the hypothesis that aberrant calcineurin or GSK-3 $\beta$ signaling contributes to APP-induced memory defects. To reduce calcineurin activation, we expressed UAS-RNAi-calcineurin $(R N A i-C a N)$ in APP overexpressing flies, which had been shown to effectively restore calcineurin perturbations in APP flies (Shaw and Chang, 2013). Reducing calcineurin signifi- 


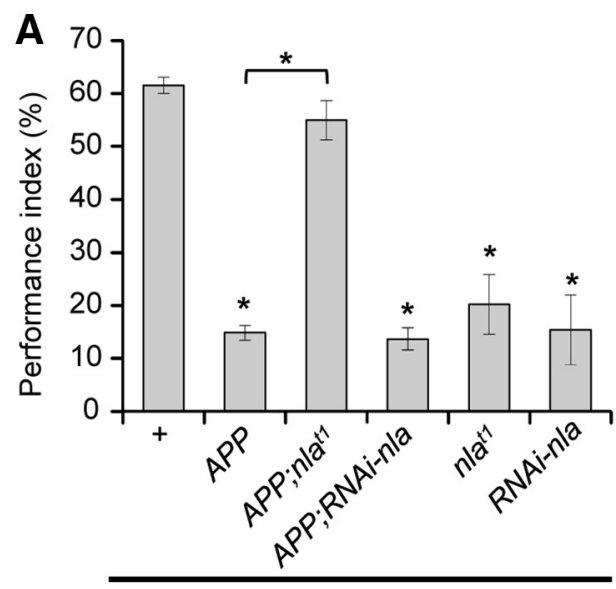

B

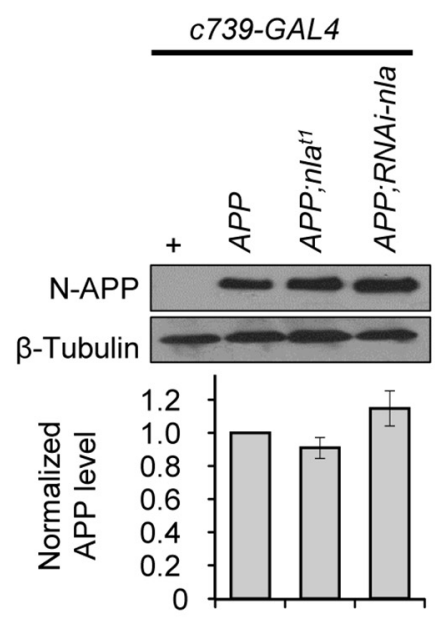

C739-GAL4
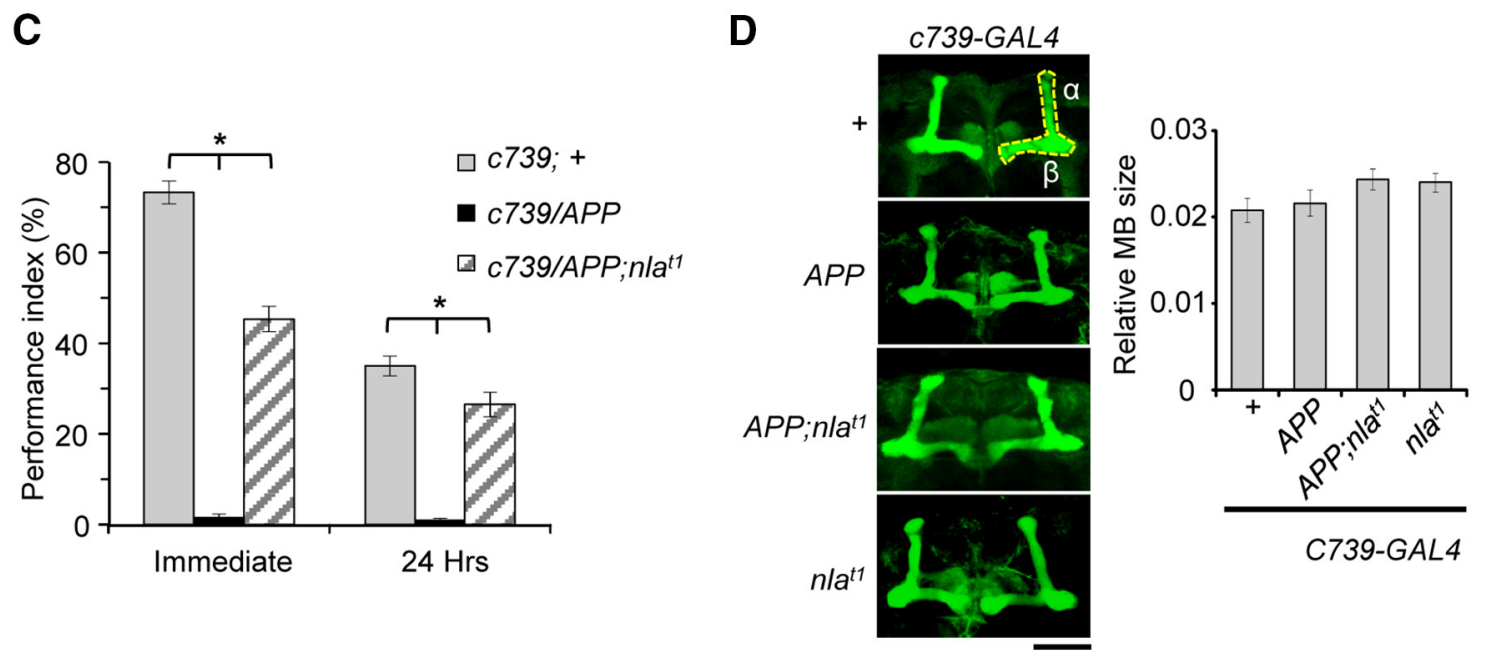

Figure 1. Co-upregualtion of APP and Nebula rescues APP-induced STM and LTM impairments. A, Aversive associative memory performance of 2- to 4-d-old flies 3 min after training (STM) for the indicated genotypes. $n=18$ trials per genotype, ${ }^{*} p<0.05$ compared with control and the indicated genotypes. $\boldsymbol{B}$, Memory deficits not attributed to differences in APP expression. Western blot depicting equivalent levels of APP in the genotypes with APP upregulation driven by the C739-GAL4, a mushroom body-specific driver. APP levels were normalized to control and tubulin. $n=3$ independent experiments. C, Quantification of memory performance immediately and $24 \mathrm{~h}$ after spaced training (LTM). $n=6$ trials per genotype, ${ }^{*} p<0.05$ comparing the indicated genotypes. $D$, Representative confocal stack images of brains dissected from 2- to 4-d-old flies and stained with Fasciclin Il antibody. The area analyzed is highlighted ( $\alpha$ and $\beta$ lobes). There is no change in the gross mushroom body (MB) structure or size across genotypes. $n>6$ brains per genotype. Scale bar, $50 \mu \mathrm{m}$. All values indicate mean \pm SEM.

Table 1. Sensorimotor responses of 2- to 4-d-old flies

\begin{tabular}{llll}
\hline & \% Shock avoidance & \% MCH avoidance & \% OCT avoidance \\
\hline C739/+ (control) & $86.72 \pm 1.92$ & $87.93 \pm 2.34$ & $81.13 \pm 2.30$ \\
C739/UAS-APP & $84.15 \pm 2.00$ & $90.46 \pm 2.56$ & $84.32 \pm 2.41$ \\
C739/UAS-APP;UAS-nla ${ }^{t 1}$ & $92.93 \pm 3.02$ & $86.96 \pm 2.00$ & $89.23 \pm 2.86$ \\
C739/UAS-APP;UAS-RNAi-nla & $93.62 \pm 1.61$ & $96.17 \pm 1.66$ & $89.83 \pm 5.10$ \\
C739;UAS-nla ${ }^{t 1}$ & $91.47 \pm 2.75$ & $92.81 \pm 2.64$ & $90.07 \pm 1.07$ \\
C739;UAS-RNAi-nla & $89.48 \pm 1.92$ & $86.71 \pm 1.92$ & $87.35 \pm 2.33$ \\
C739/UAS-APP;UAS-PKA & $81.29 \pm 2.45$ & $82.38 \pm 3.02$ & $90.75 \pm 2.26$ \\
sgg $;$; (739/UAS-APP $_{\text {C739/UAS-APP;UAS-RNAi-CaN }}$ & $92.71 \pm 3.48$ & $88.42 \pm 1.79$ & $89.32 \pm 2.74$ \\
\hline
\end{tabular}

Drosophila of all genotypes avoided shock, MCH, and OCT. $n=6$ independent trials per genotype and per condition.

cantly improved STM in flies with APP overexpression (APP; RNAi-CaN; Fig. 2A; Table 1), confirming that abnormal calcineurin activity contributes to STM defects in this fly AD model. Conversely, reducing GSK- $3 \beta$ activation using a mutant of fly GSK- $3 \beta$ shown previously to rescue APP-induced transport defects was not sufficient to rescue APP-induced STM defects
$\left(\mathrm{sgg}^{1}\right.$;APP; Fig. 2A; Shaw and Chang, 2013). This suggests that activation of GSK-3 $\beta$ signaling is not a main cause of memory defects in flies with APP overexpression.

Calcineurin has been shown to influence downstream PKA signaling, a kinase known for its importance in learning and memory pathways (Drain et al., 1991; Skoulakis et al., 1993; Gervasi et al., 2010). Therefore, we tested the hypothesis that APP overexpression also affects STM through PKA signaling. Figure $2 A$ shows that APP-induced STM defect was improved significantly by wild-type PKA upregulation, supporting the notion that APP overexpression also acts via PKA signaling to influence STM. To confirm that flies with APP overexpression alters PKA signaling, we directly measured PKA enzymatic activity using fly head extracts isolated from transgenic flies expressing the indicated transgene in all neurons. APP overexpression dramatically reduced PKA activity compared with the control, whereas Nebula co-upregulation restored PKA activity close to normal (Fig. 2B). Consistent with previous reports, we find that manipulation of Nebula alone also led to altered PKA activities (Fig. 2B; Chang et 
A

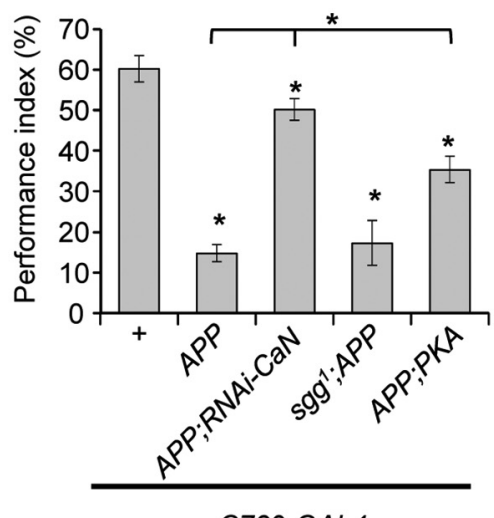

C739-GAL4
B

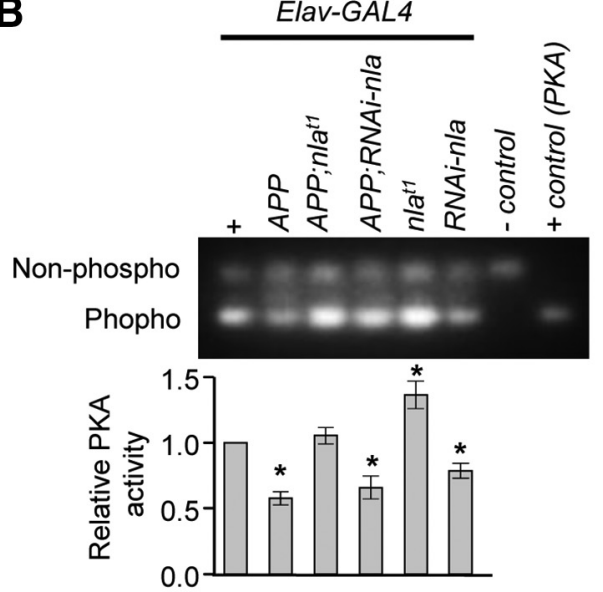

c Elav-GAL4
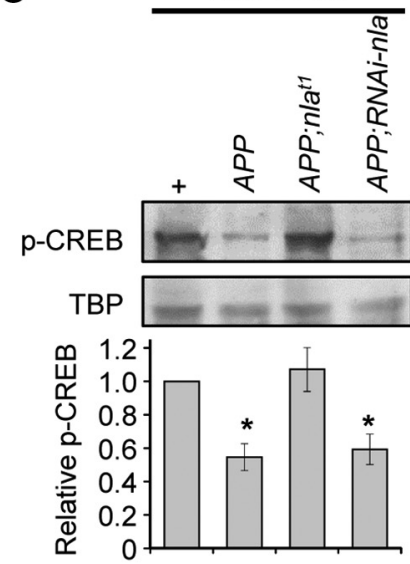

Figure 2. APP-mediated impairments in STM are rescued by restoring calcineurin or PKA activity. (A) STM performance index for $2-4 \mathrm{~d}$-old flies of the indicated genotypes. $n=18$ trials. $B$, PKA activity compared across genotypes. Quantification represents assays normalized to the control. $n=12$ independent experiments. C, Western blot analysis of phosphorylated CREB levels using nuclear extracts prepared from 2- to 4-d-old flies. Co-upregulation of APP and Nebula restored phosphorylated CREB levels to that of the control. The nuclear TATA binding protein (TBP) was used as a loading control. $n=8$ independent experiments. All values are mean \pm SEM. ${ }^{*} p<0.05$ compared with control and the indicated genotypes.

al., 2003). Note that PKA upregulation did not perfectly rescue APP-induced STM defects, indicating that either an exact level of PKA or the proper spatiotemporal activation of PKA is crucial for normal memory as shown by previous reports (Chang et al., 2003; Yamazaki et al., 2007; Gervasi et al., 2010). PKA is also a known regulator of LTM through its phosphorylation of CREB, which is thought to activate CRE-dependent gene expression crucial for the establishment of LTM (Drain et al., 1991; Yin et al., 1994). Indeed, flies with APP overexpression showed a correspondingly low level of CREB phosphorylation, whereas co-upregulation of Nebula and APP restored CREB phosphorylation to normal (Fig. 2C). These results imply that Nebula likely restored LTM defects by preserving CREB phosphorylation.

\section{Co-upregulation of APP and Nebula impairs memory performance of old flies}

The finding that Nebula co-upregulation significantly improved the memory performance of young flies with APP overexpression could potentially have important clinical implications; therefore, we assayed whether such protective effects persist into an old age. Similar to humans and other animal models, Drosophila show memory decline as a function of age as seen in our control flies (Fig. 3A; Tamura et al., 2003; Yamazaki et al., 2007; Tonoki and Davis, 2012). However, despite restoring STM to normal in young flies $<10 \mathrm{~d}$ old, Nebula upregulation did not protect against APP-induced STM defects in older flies. Furthermore, the much steeper decline in memory performance in flies overexpressing APP and Nebula during aging compared with the control flies raised the possibility that either Nebula is no longer effective in protecting against APP-induced memory impairments as a function of age or that chronic upregulation of Nebula contributes to the poor STM performance in old flies (Fig. 3A; Table 2).

Overexpression of APP and Nebula retains the ability to inhibit calcineurin but exacerbates mitochondrial dysfunctions during aging

To discern these two possibilities, we first confirmed that the C739-GAL4 driver is as effective in driving expression in old flies as in young flies. This is indeed the case because the level of APP expression is the same in young and old flies (Fig. 3B). We also examined the mushroom body structure in aged flies that are between 42 and $45 \mathrm{~d}$ of age. Akin to the young flies, mushroom body structure did not differ between genotypes (Fig. $3 C$ ), suggesting that this change in the ability of Nebula to restore memory performance is not attributable to an agedependent change in mushroom body structure. Next, we asked whether Nebula loses its ability to inhibit calcineurin in older flies. Calcineurin activity assay revealed that aging led to a significant increase in calcineurin activity even in the control flies by $45 \mathrm{~d}$ old (Fig. 3D). Nevertheless, Nebula overexpression still effectively prevented APP-induced calcineurin hyperactivation compared with age-matched control flies (Fig. $3 D$ ). Thus, a change in the ability of Nebula to inhibit calcineurin is not a primary cause of STM impairments in older flies with $A P P$ and nebula overexpression.

In addition to acting as an inhibitor of calcineurin, Nebula/ DSCR1 has also been shown to interact with the adenine nucleotide translocator to regulate mitochondrial function (Chang and Min, 2005; Peiris et al., 2014). Therefore, we tested the hypothesis that nebula overexpression exacerbates mitochondrial dysfunction during aging. First, we measured the cellular ATP content, which is indicative of the overall mitochondrial function. Neuronal overexpression of APP or nebula alone in young flies led to mitochondrial dysfunction as measured by the decrease in the overall ATP content (Fig. $3 E$ ). Interestingly, despite restoring APP-induced STM defects in young flies, Nebula and APP co-upregulation still showed a similarly reduced ATP content (Fig. $3 E$ ), indicating that mitochondrial dysfunction, at least in young flies, is not sufficient to trigger STM defects. However, in aged flies, Nebula and APP overexpression significantly enhanced mitochondrial dysfunction by causing a $>67 \%$ decrease in the overall ATP content in old flies ( 45 vs $3 \mathrm{~d}$ old $)$. Control and flies overexpressing APP only displayed an $\sim 20 \%$ reduction in the overall ATP content as a result of aging (Fig. $3 E$ ). Nebula overexpression alone also caused severe ATP depletion during aging similar to flies with APP and Nebula overexpression, indicating that Nebula is dominant in this phenotype. These data support 
A

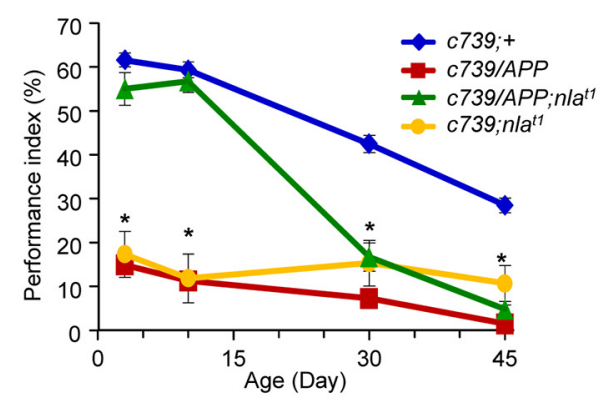

D

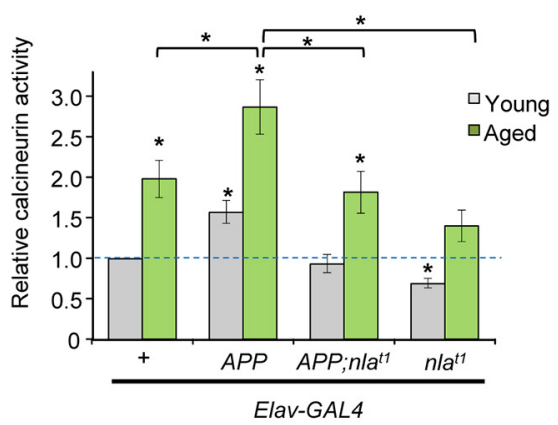

B

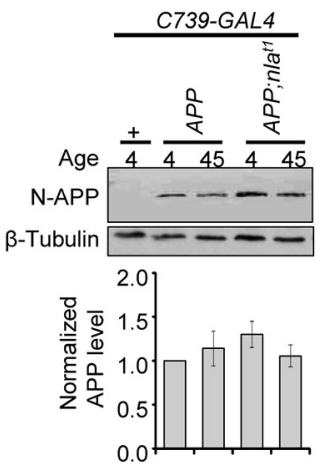

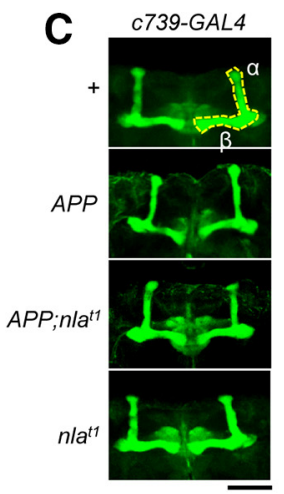

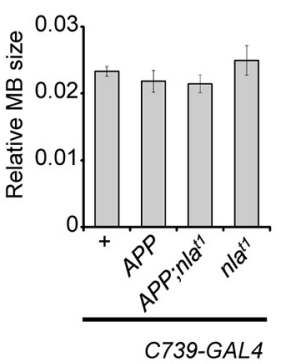

$\mathbf{E}$

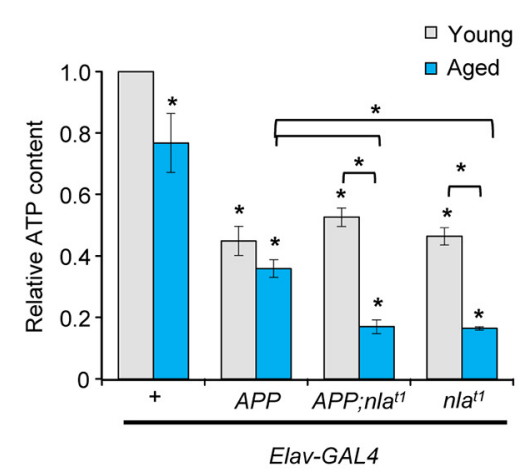

$\mathbf{F}$

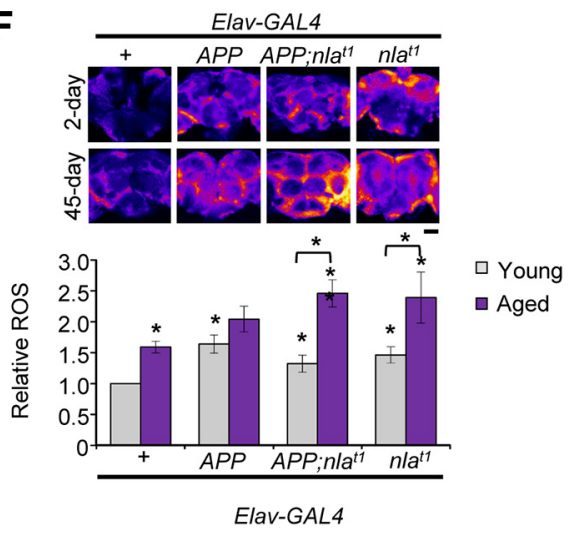

Figure 3. Co-upregulation of APP and Nebula enhances age-dependent memory impairments and exacerbates mitochondrial dysfunctions. $A$, Quantification of STM during aging. $n=18$ trials, ${ }^{*} p<0.05$ compared with age-matched control flies and flies overexpressing APP or Nebula at 3 and $10 \mathrm{~d}$. At 30 and $45 \mathrm{~d},{ }^{*} p<0.05$ compared with age-matched control flies and APP, APP and Nebula, or Nebula overexpressing flies. $\boldsymbol{B}$, There is no change in the effectiveness of the C739-GAL4 driver during aging. Western blot shows similar levels of APP in young flies between 2 and 4 or 42 and 45 dold expressing the APP transgene driven by the C739-GAL 4 driver. APP levels were normalized to control flies and tubulin. $n=3$ independent experiments. $C$, Images of dissected brains from 42- to 45-d-old flies stained with Fasciclin II antibody. The $\alpha$ and $\beta$ lobes analyzed are highlighted. There is no change in the gross mushroom body structure or size across genotypes in aged flies. $n>6$ brains per genotype. $\boldsymbol{D}$, Aging causes an increase in calcineurin activity. Nebula still effectively inhibits calcineurin in 42- to 45 -d-old flies (aged flies). $n=11$ independent experiments. $\boldsymbol{E}$, Nebula upregulation exacerbates decline in the overall ATP content in aged flies. All values were normalized to young flies done in parallel experiments. $n=8$ independent experiments for young and old flies. $\boldsymbol{F}$, Pseudocolored images and quantification of dihydroethidium staining in the brains of young and aged Drosophila. $n=5$ independent experiments per genotype per condition. Scale bars: $\boldsymbol{C}, \boldsymbol{F}, 50 \mu \mathrm{m}$. All values represent mean \pm SEM. For $\boldsymbol{D}$ and $\boldsymbol{E},{ }^{*} p<0.05$ compared with young controls or as indicated.

Table 2. Sensorimotor responses of 42- to 45-d-old flies

\begin{tabular}{llll}
\hline & \% Shock avoidance & \% MCH avoidance & \% 0CT avoidance \\
\hline C739/+ (control) & $89.68 \pm 2.20$ & $90.85 \pm 1.51$ & $88.88 \pm 2.20$ \\
C739/UAS-APP & $82.34 \pm 1.95$ & $88.69 \pm 3.46$ & $93.52 \pm 2.31$ \\
C739/UAS-APP;UAS-nla $^{t 7}$ & $86.17 \pm 4.63$ & $84.27 \pm 2.33$ & $83.29 \pm 2.85$ \\
C739;UAS-nla $^{t 7}$ & $92.85 \pm 3.24$ & $84.04 \pm 2.29$ & $88.03 \pm 5.74$ \\
\hline
\end{tabular}

No change in sensorimotor response was observed across genotypes. $n=6$ independent trials per genotype and per condition.

the notion that upregulation of Nebula further exacerbates mitochondrial dysfunction during aging. Second, we measured the relative ROS levels in flies using dihydroethidium staining. Chronic co-upregulation of APP and Nebula resulted in a significantly greater increase in ROS levels during aging compared with control or APP flies, confirming that Nla upregulation causes mitochondrial dysfunction and triggers ROS elevation (Fig. $3 F$ ). Previous studies examining the link between oxidative stress and ROS on STM revealed that STM of older flies is particularly sensitive to perturbation of genes implicated in combating ROS, whereas young flies are not affected by decreases in antioxidant enzymes or ROS elevation (Haddadi et al., 2014). Thus, the increase in ROS and decline in ATP content seen in old flies overexpressing APP and Nebula likely accelerated age-dependent memory decline.
Transient Nebula upregulation or acute inhibition of calcineurin rescues APP-induced memory impairments in aged flies

The bimodal effect of Nebula upregulation on APP-induced memory loss is age dependent, leading us to investigate whether changes in basic cellular physiology during aging is a main underlying cause or that acute versus chronic upregulation of Nebula exerts different effects on APP-induced memory loss. To differentiate these two possibilities, we transiently upregulated APP with or without Nebula in either young or old flies using an inducible mushroom body driver (MB-GeneSwitchGAL4). MB-GeneSwitch-GAL4 allows temporal control of transgene expression specifically in the mushroom body neurons after RU486 administration (Mao et al., 2004). We find that transient upregulation of APP in the mushroom bodies of adult flies was sufficient to trigger STM defects (Fig. 4A; Table 3 ), similar to results obtained using C739-GAL4 driver. However, acute co-upregulation of APP and Nebula in either young or aged flies effectively rescued the APP-induced STM defect, indicating that aging per se is not the cause of the inability of Nebula to rescue APP phenotypes (Fig. 4A,B). Furthermore, selective upregulation of Nebula in old flies no longer impaired STM (unlike the young flies), presumably by counterbalancing increased calcineurin activity in aged flies (Fig. 3D). 
If short-term instead of chronic upregulation of Nebula is indeed beneficial for protecting against APP-induced memory loss, we reasoned that acute inhibition of calcineurin should be able to ameliorate STM loss even in the presence of chronic APP upregulation. To test this hypothesis, we pharmacologically inhibited calcineurin by feeding aged flies overexpressing APP with either $30 \mu \mathrm{M}$ cyclosporin A or $30 \mu \mathrm{M}$ FK506, inhibitors of calcineurin. Either cyclosporin A or FK506 effectively rescued the STM defects seen in aged APP overexpressing flies to values seen for age-matched, untreated control flies (Fig. 4C; Table 4). Acute inhibition of calcineurin also significantly improved the STM of 45-d-old control flies, likely because these drugs alleviated the increase in calcineurin activity seen in aged control flies (Fig. 4D). These data suggest that the inability of Nebula to protect against memory loss in old flies with $A P P$ overexpression is not attributable to irreversible damages caused by $A P P$ overexpression but rather to chronic Nebula upregulation. Nevertheless, we were not able to restore STM to young control levels despite restoring calcineurin activity in old flies, suggesting that aging also triggers other cellular events that adversely affect memory performance (Eckles-Smith et al., 2000; Liu et al., 2003; Yamazaki et al., 2007; Wang et al., 2011; Gupta et al., 2013). Together, our findings further reveal that calcineurin dyshomeostasis contributes to memory impairment during aging and that acute inhibition of calcineurin can ameliorate memory deterioration during aging in control and a fly model for $\mathrm{AD}$.

\section{Discussion}

Nebula/DSCR1 and APP have been shown to be upregulated in both DS and AD (Cook et al., 2005; Sun et al., 2011), but the effect of this upregulation on memory was not known. Our findings reveal a complex and novel role for Nebula/DSCR1 upregulation in regulating APP-induced memory loss during aging. First, we show that upregulation of Nebula initially protects against APPinduced memory impairments by restoring calcineurinmediated signaling in young flies. Second, we find that persistent upregulation of Nebula contributes to the poor memory performance of APP and Nebula flies during aging. Third, we show that aging is accompanied by elevations in calcineurin activity, and acute inhibition of calcineurin can improve the memory performance of older control and APP overexpressing flies. Together, our results suggest that Nebula/DSCR1 upregulation may delay the onset of memory loss but contribute to progressive dementia in older individuals with DS. Therefore, our study has wide implications for memory loss during natural aging and in $\mathrm{AD}$ and DS and shines light on restoring calcineurin or regulating Nebula/DSCR1 levels as potential therapeutic strategies for agedependent memory loss.
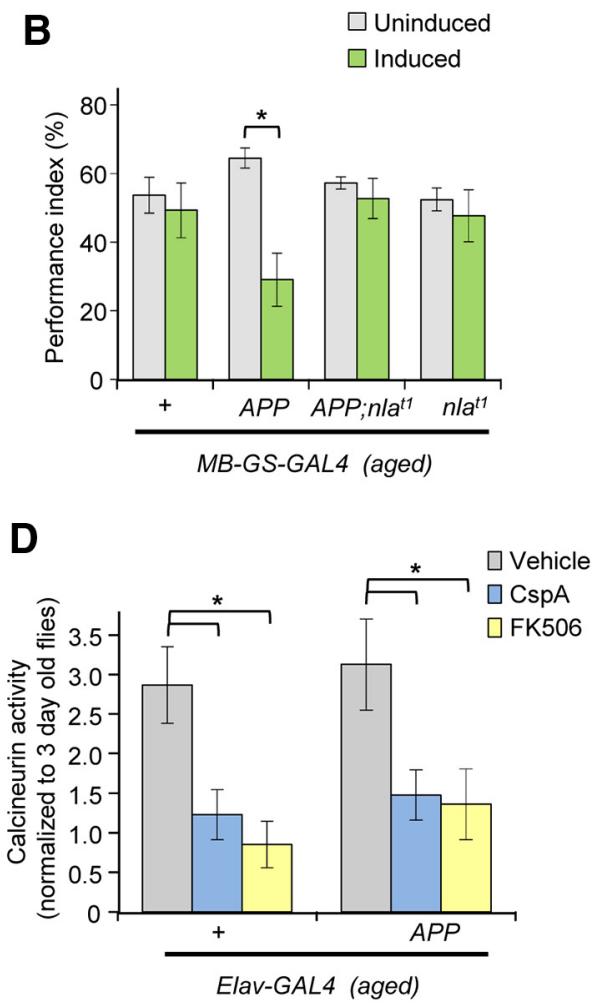

Elav-GAL4 (aged)

Figure 4. Acute inhibition of calcineurin by transient Nebula upregulation or pharmacological treatment enhances STM in aged flies. STM quantification for 2- to 4-d-old flies (young) $(\boldsymbol{A})$ and aged flies (30-33 d old) with or without RU486 induction (B).

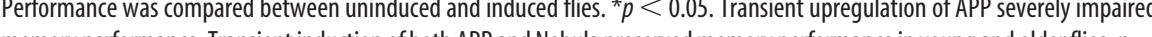
with either cyclosporin A (CspA) or FK506 enhanced memory performance of aged control flies. Pharmacological inhibition of or drug. Drug-treated flies were treated for $3 \mathrm{~d}$ with either $30 \mu \mathrm{m}$ cyclosporin A or FK506. Quantification represents mean \pm SEM $n=5$ independent experiments. ${ }^{*} p<0.05$ compared with the indicated conditions.

Table 3. Sensorimotor responses of $M B-G e n e S w i t c h-G A L 4$ containing drivers before and after induction

\begin{tabular}{cccc}
\hline & \% Shock avoidance & \% MCH avoidance & \% OCT avoidance \\
\hline $\begin{array}{c}\text { Young flies }(2-5 \mathrm{~d}) \\
\text { UAS-APP;MB-GS } \\
\text { Uninduced }\end{array}$ & $89.21 \pm 3.74$ & $98.29 \pm 1.10$ & $98.84 \pm 0.73$ \\
$\quad$ Induced & $87.87 \pm 4.15$ & $95.99 \pm 2.40$ & $97.31 \pm 1.12$ \\
$\begin{array}{c}\text { MB-GS/UAS-nlat1 } \\
\text { Uninduced }\end{array}$ & $94.79 \pm 1.74$ & $97.44 \pm 0.96$ & $99.31 \pm 0.69$ \\
$\quad$ Induced & $94.18 \pm 2.35$ & $97.46 \pm 1.25$ & $95.43 \pm 3.77$ \\
Aged flies (30-33 d) & & & \\
UAS-APP;MB-GS & & & \\
Uninduced & $76.94 \pm 4.47$ & $82.14 \pm 3.99$ & $93.11 \pm 1.16$ \\
Induced & $83.55 \pm 4.82$ & $82.08 \pm 2.83$ & $93.37 \pm 1.27$ \\
MB-GS/UAS-nlat1 & & & \\
Uninduced & $86.07 \pm 2.98$ & $89.32 \pm 2.65$ & $92.72 \pm 2.10$ \\
Induced & $92.88 \pm 1.39$ & $84.78 \pm 2.68$ & $92.88 \pm 1.39$ \\
\hline
\end{tabular}

STM defects are not caused by changes in sensorimotor responses. $n=6$ independent trials per genotype and per condition.

\section{Mechanisms for Nebula rescue of APP-induced memory defects}

Nebula/DSCR1 is a multifunctional protein that inhibits calcineurin and modulates mitochondria function and oxidative stress response (Ermak et al., 2002; Chang et al., 2003; Chang and 


\begin{tabular}{|c|c|c|c|}
\hline & \% Shock avoidance & \% MCH avoidance & \% OCT avoidance \\
\hline \multicolumn{4}{|l|}{ (739/+ (control) } \\
\hline DMSO & $95.98 \pm 1.71$ & $91.22 \pm 3.91$ & $85.99 \pm 3.77$ \\
\hline $30 \mu \mathrm{M}$ CspA & $83.19 \pm 5.44$ & $85.51 \pm 2.36$ & $95.43 \pm 2.23$ \\
\hline $30 \mu \mathrm{M}$ FK506 & $88.53 \pm 3.64$ & $88.67 \pm 4.30$ & $90.86 \pm 1.89$ \\
\hline \multicolumn{4}{|l|}{ C739;UAS-APP } \\
\hline DMSO & $91.11 \pm 1.21$ & $84.16 \pm 2.93$ & $85.06 \pm 2.41$ \\
\hline $30 \mu \mathrm{M} \operatorname{CspA}$ & $95.84 \pm 2.13$ & $88.38 \pm 2.41$ & $89.04 \pm 4.81$ \\
\hline $30 \mu \mathrm{m}$ FK506 & $88.69 \pm 4.96$ & $95.94 \pm 1.84^{*}$ & $91.15 \pm 3.55$ \\
\hline
\end{tabular}

$n=6$ independent trials per genotype and per condition. ${ }^{*} p<0.05$ for C739;UAS-APP compared with DMSO treatment. CspA, Cyclosporin A.

Min, 2005; Hoeffer et al., 2007; Porta et al., 2007; Dierssen et al., 2011; Sun et al., 2011, 2014; Martin et al., 2012; Peiris et al., 2014). Previous reports have indicated that upregulation of either Nebula/DSCR1 or APP alone impaired memory (Chang et al., 2003; Hoeffer et al., 2007; Sarantseva et al., 2009; Simón et al., 2009; Dierssen et al., 2011; Martin et al., 2012). Therefore, it is unexpected that co-upregulation of Nebula and APP restored both STM and LTM of young flies. Such results were confirmed using two different mushroom body drivers: C739-Gal4 and MBGeneSwitch-Gal4 (Figs. 1, 4). The use of mushroom body drivers is advantageous because it circumvented the problem of locomotor defects associated with pan-neuronal APP overexpression (Shaw and Chang, 2013), and the Drosophila mushroom bodies has been shown to be structures important for memory retrieval (Dubnau et al., 2001; McGuire et al., 2001; Séjourné et al., 2011), a process disrupted in AD-related memory loss (Gold and Budson, 2008; Nellessen et al., 2015). Our biochemical and behavioral data indicate that Nebula rescues memory loss by correcting APP-induced calcineurin hyperactivation, as well as deficits in PKA activity and CREB phosphorylation. These results are consistent with the finding that a fine balance in calcineurin and PKA signaling are crucial for normal memory (Drain et al., 1991; Skoulakis and Davis, 1996; Malleret et al., 2001; Zeng et al., 2001; Chang et al., 2003; Yamazaki et al., 2007). However, genetics and behavioral data indicate that restoring GSK-3 $\beta$ hyperactivation in APP overexpressing flies shown previously to rescue axonal transport defects (Shaw and Chang, 2013) is not sufficient to rescue the memory deficits. Furthermore, because APP and Nebula overexpressing flies restored STM despite the presence of mitochondrial dysfunction, our data highlight that correcting calcineurin disturbances in younger flies is more beneficial for memory than restoring mitochondrial dysfunction.

\section{Contribution of Nebula to memory decline during aging}

Age-associated memory impairment occurs in many species ranging from Drosophila to humans (Bishop et al., 2010); understanding mechanisms contributing to this process may provide useful insights into changes responsible for dementia in agerelated neurological disorders such as AD. Our data provide two important revelations concerning cellular changes contributing to age-dependent memory decline. First, our finding highlight that elevation in calcineurin activity is a previously unidentified mechanism contributing to memory decline during natural aging in Drosophila. This is supported by biochemical data showing increases in calcineurin activity during aging, as well as behavioral data illustrating that transient pharmacological inhibition of calcineurin can significantly improve the memory performance of old wild-type flies. Second, we find chronic upregulation of Nebula also triggers severe mitochondrial dysfunction that can override the protective effect of calcineurin inhibition by Nebula in flies overexpressing APP, implying that long-term Nebula upregulation may contribute to memory loss in APP overexpressing flies during aging. By measuring ATP content and ROS levels within the fly brain, we show that chronic Nebula overexpression both on its own or in the presence of APP significantly exacerbated mitochondrial dysfunction and elevated ROS. Conversely, short-term upregulation of APP and Nebula in aged flies or transient pharmacological inhibition of calcineurin in older flies with chronic APP overexpression both resulted in normal STM performance compared with age-matched control. These results support the notion that chronic Nebula upregulation during aging enhances age-dependent memory impairments in flies with APP overexpression and further suggest that proper mitochondrial function plays an important role in memory preservation in older flies. This interpretation is supported by a report that STM of older flies is particularly sensitive to mutations that elevate ROS, whereas the STM of younger flies is not affected by ROS elevation (Haddadi et al., 2014).

\section{Implications for memory decline in $\mathrm{DS}$ and $\mathrm{AD}$}

We propose that Nebula/DSCR1 upregulation plays a twopronged role in regulating APP-induced phenotypes in DS. Nebula/DSCR1 upregulation initially protects against APP-induced memory loss by correcting calcineurin-mediated signaling, but chronic Nebula/DSCR1 overexpression triggers severe mitochondrial dysfunction and ROS elevation that potentially leads to rapid decline in memory during aging in DS. Interestingly, $\beta$-amyloid has been shown to trigger upregulation of DSCR1, and DSCR1 upregulation is also associated with tau hyperphosphorylation (Ermak et al., 2001; Ermak and Davies, 2003; Lloret et al., 2011). It will be particularly interesting in the future to study the effects of Nebula/DSCR1 in modifying $\beta$-amyloid and tau-associated memory impairments and to test whether preventing mitochondrial dysfunction and ROS elevations in older animals while correcting calcineurin signaling could alleviate memory problems associated with Nebula/DSCR1 and APP overexpression as seen in some cases of DS and AD.

\section{References}

Akalal DB, Wilson CF, Zong L, Tanaka NK, Ito K, Davis RL (2006) Roles for Drosophila mushroom body neurons in olfactory learning and memory. Learn Mem 13:659-668. CrossRef Medline

Aramburu J, Rao A, Klee CB (2000) Calcineurin: from structure to function. Curr Top Cell Regul 36:237-295. Medline

Bishop NA, Lu T, Yankner BA (2010) Neural mechanisms of ageing and cognitive decline. Nature 464:529-535. CrossRef Medline

Bush A, Beail N (2004) Risk factors for dementia in people with down syndrome: issues in assessment and diagnosis. Am J Ment Retard 109:83-97. CrossRef Medline

Carmine-Simmen K, Proctor T, Tschäpe J, Poeck B, Triphan T, Strauss R, Kretzschmar D (2009) Neurotoxic effects induced by the Drosophila amyloid-beta peptide suggest a conserved toxic function. Neurobiol Dis 33:274-281. CrossRef Medline

Chakraborty R, Vepuri V, Mhatre SD, Paddock BE, Miller S, Michelson SJ, Delvadia R, Desai A, Vinokur M, Melicharek DJ, Utreja S, Khandelwal P, Ansaloni S, Goldstein LE, Moir RD, Lee JC, Tabb LP, Saunders AJ, Marenda DR (2011) Characterization of a Drosophila Alzheimer's disease model: pharmacological rescue of cognitive defects. PLoS One 6:e20799. CrossRef Medline

Chang KT, Min KT (2005) Drosophila melanogaster homolog of Down syndrome critical region 1 is critical for mitochondrial function. Nat Neurosci 8:1577-1585. CrossRef Medline

Chang KT, Shi YJ, Min KT (2003) The Drosophila homolog of Down's syndrome critical region 1 gene regulates learning: implications for mental retardation. Proc Natl Acad Sci U S A 100:15794-15799. CrossRef Medline 
Chartier-Harlin MC, Crawford F, Houlden H, Warren A, Hughes D, Fidani L, Goate A, Rossor M, Roques P, Hardy J, Mullan M (1991) Early-onset Alzheimer's disease caused by mutations at codon 717 of the betaamyloid precursor protein gene. Nature 353:844-846. CrossRef Medline

Chen HK, Fernandez-Funez P, Acevedo SF, Lam YC, Kaytor MD, Fernandez MH, Aitken A, Skoulakis EM, Orr HT, Botas J, Zoghbi HY (2003) Interaction of Akt-phosphorylated ataxin-1 with 14-3-3 mediates neurodegeneration in spinocerebellar ataxia type 1. Cell 113:457-468. CrossRef Medline

Clark IE, Dodson MW, Jiang C, Cao JH, Huh JR, Seol JH, Yoo SJ, Hay BA, Guo M (2006) Drosophila pink1 is required for mitochondrial function and interacts genetically with parkin. Nature 441:1162-1166. CrossRef Medline

Cook CN, Hejna MJ, Magnuson DJ, Lee JM (2005) Expression of calcipres$\sin 1$, an inhibitor of the phosphatase calcineurin, is altered with aging and Alzheimer's disease. J Alzheimers Dis 8:63-73. Medline

Davis RL (2011) Traces of Drosophila memory. Neuron 70:8-19. CrossRef Medline

Dierssen M, Arqué G, McDonald J, Andreu N, Martínez-Cué C, Flórez J, Fillat C (2011) Behavioral characterization of a mouse model overexpressing DSCR1/RCAN1. PLoS One 6:e17010. CrossRef Medline

Drain P, Folkers E, Quinn WG (1991) cAMP-dependent protein kinase and the disruption of learning in transgenic flies. Neuron 6:71-82. CrossRef Medline

Dubnau J, Tully T (1998) Gene discovery in Drosophila: new insights for learning and memory. Annu Rev Neurosci 21:407-444. CrossRef Medline

Dubnau J, Grady L, Kitamoto T, Tully T (2001) Disruption of neurotransmission in Drosophila mushroom body blocks retrieval but not acquisition of memory. Nature 411:476-480. CrossRef Medline

Eckles-Smith K, Clayton D, Bickford P, Browning MD (2000) Caloric restriction prevents age-related deficits in LTP and in NMDA receptor expression. Brain Res Mol Brain Res 78:154-162. CrossRef Medline

Ermak G, Davies KJ (2003) DSCR1(Adapt78)—a Janus gene providing stress protection but causing Alzheimer's disease? IUBMB Life 55:29-31. CrossRef Medline

Ermak G, Morgan TE, Davies KJ (2001) Chronic overexpression of the calcineurin inhibitory gene DSCR1 (Adapt78) is associated with Alzheimer's disease. J Biol Chem 276:38787-38794. CrossRef Medline

Ermak G, Harris CD, Davies KJ (2002) The DSCR1 (Adapt78) isoform 1 protein calcipressin 1 inhibits calcineurin and protects against acute calcium-mediated stress damage, including transient oxidative stress. FASEB J 16:814-824. CrossRef Medline

Feany MB, Bender WW (2000) A Drosophila model of Parkinson's disease. Nature 404:394-398. CrossRef Medline

Fuentes JJ, Pritchard MA, Planas AM, Bosch A, Ferrer I, Estivill X (1995) A new human gene from the Down syndrome critical region encodes a proline-rich protein highly expressed in fetal brain and heart. Hum Mol Genet 4:1935-1944. CrossRef Medline

Fuentes JJ, Genescà L, Kingsbury TJ, Cunningham KW, Pérez-Riba M, Estivill $\mathrm{X}$, de la Luna S (2000) DSCR1, overexpressed in Down syndrome, is an inhibitor of calcineurin-mediated signaling pathways. Hum Mol Genet 9:1681-1690. CrossRef Medline

Gervasi N, Tchénio P, Preat T (2010) PKA dynamics in a Drosophila learning center: coincidence detection by rutabaga adenylyl cyclase and spatial regulation by dunce phosphodiesterase. Neuron 65:516-529. CrossRef Medline

Goate A, Chartier-Harlin MC, Mullan M, Brown J, Crawford F, Fidani L, Giuffra L, Haynes A, Irving N, James L, Mant R, Newton P, Rooke K, Roques P, Talbot C, Pericak-Vance M, Roses A, Williamson R, Rossor M, Owen M, Hardy J (1991) Segregation of a missense mutation in the amyloid precursor protein gene with familial Alzheimer's disease. Nature 349:704-706. CrossRef Medline

Gold CA, Budson AE (2008) Memory loss in Alzheimer's disease: implications for development of therapeutics. Expert Rev Neurother 8:18791891. CrossRef Medline

Grady CL, Furey ML, Pietrini P, Horwitz B, Rapoport SI (2001) Altered brain functional connectivity and impaired short-term memory in Alzheimer's disease. Brain 124:739-756. CrossRef Medline

Greeve I, Kretzschmar D, Tschäpe JA, Beyn A, Brellinger C, Schweizer M, Nitsch RM, Reifegerste R (2004) Age-dependent neurodegeneration and Alzheimer-amyloid plaque formation in transgenic Drosophila. J Neurosci 24:3899-3906. CrossRef Medline

Guo M (2010) What have we learned from Drosophila models of Parkinson's disease? Prog Brain Res 184:3-16. Medline

Gupta VK, Scheunemann L, Eisenberg T, Mertel S, Bhukel A, Koemans TS, Kramer JM, Liu KS, Schroeder S, Stunnenberg HG, Sinner F, Magnes C, Pieber TR, Dipt S, Fiala A, Schenck A, Schwaerzel M, Madeo F, Sigrist SJ (2013) Restoring polyamines protects from age-induced memory impairment in an autophagy-dependent manner. Nat Neurosci 16:14531460. CrossRef Medline

Haddadi M, Jahromi SR, Sagar BK, Patil RK, Shivanandappa T, Ramesh SR (2014) Brain aging, memory impairment and oxidative stress: a study in Drosophila melanogaster. Behav Brain Res 259:60-69. CrossRef Medline

Head E, Azizeh BY, Lott IT, Tenner AJ, Cotman CW, Cribbs DH (2001) Complement association with neurons and beta-amyloid deposition in the brains of aged individuals with Down Syndrome. Neurobiol Dis 8:252-265. CrossRef Medline

Hoeffer CA, Dey A, Sachan N, Wong H, Patterson RJ, Shelton JM, Richardson JA, Klann E, Rothermel BA (2007) The Down syndrome critical region protein RCAN1 regulates long-term potentiation and memory via inhibition of phosphatase signaling. J Neurosci 27:13161-13172. CrossRef Medline

Iijima K, Liu HP, Chiang AS, Hearn SA, Konsolaki M, Zhong Y (2004) Dissecting the pathological effects of human Abeta40 and Abeta42 in Drosophila: a potential model for Alzheimer's disease. Proc Natl Acad Sci U S A 101:6623-6628. CrossRef Medline

Iijima-Ando K, Iijima K (2010) Transgenic Drosophila models of Alzheimer's disease and tauopathies. Brain Struct Funct 214:245-262. CrossRef Medline

Jackson GR, Wiedau-Pazos M, Sang TK, Wagle N, Brown CA, Massachi S, Geschwind DH (2002) Human wild-type tau interacts with wingless pathway components and produces neurofibrillary pathology in Drosophila. Neuron 34:509-519. CrossRef Medline

Kasuga K, Shimohata T, Nishimura A, Shiga A, Mizuguchi T, Tokunaga J, Ohno T, Miyashita A, Kuwano R, Matsumoto N, Onodera O, Nishizawa M, Ikeuchi T (2009) Identification of independent APP locus duplication in Japanese patients with early-onset Alzheimer disease. J Neurol Neurosurg Psychiatry 80:1050-1052. CrossRef Medline

Klekociuk SZ, Summers MJ (2014) Lowered performance in working memory and attentional sub-processes are most prominent in multi-domain amnestic mild cognitive impairment subtypes. Psychogeriatrics 14:63-71. CrossRef Medline

Leverenz JB, Raskind MA (1998) Early amyloid deposition in the medial temporal lobe of young Down syndrome patients: a regional quantitative analysis. Exp Neurol 150:296-304. CrossRef Medline

Liu R, Liu IY, Bi X, Thompson RF, Doctrow SR, Malfroy B, Baudry M (2003) Reversal of age-related learning deficits and brain oxidative stress in mice with superoxide dismutase/catalase mimetics. Proc Natl Acad Sci U S A 100:8526-8531. CrossRef Medline

Lloret A, Badia MC, Giraldo E, Ermak G, Alonso MD, Pallardó FV, Davies KJ, Viña J (2011) Amyloid-beta toxicity and tau hyperphosphorylation are linked via RCAN1 in Alzheimer's disease. J Alzheimers Dis 27:701-709. CrossRef Medline

Lu B, Vogel H (2009) Drosophila models of neurodegenerative diseases. Annu Rev Pathol 4:315-342. CrossRef Medline

Malleret G, Haditsch U, Genoux D, Jones MW, Bliss TV, Vanhoose AM, Weitlauf C, Kandel ER, Winder DG, Mansuy IM (2001) Inducible and reversible enhancement of learning, memory, and long-term potentiation by genetic inhibition of calcineurin. Cell 104:675-686. CrossRef Medline

Mao Z, Roman G, Zong L, Davis RL (2004) Pharmacogenetic rescue in time and space of the rutabaga memory impairment by using Gene-Switch. Proc Natl Acad Sci U S A 101:198-203. CrossRef Medline

Martin KR, Corlett A, Dubach D, Mustafa T, Coleman HA, Parkington HC, Merson TD, Bourne JA, Porta S, Arbonés ML, Finkelstein DI, Pritchard MA (2012) Over-expression of RCAN1 causes Down syndrome-like hippocampal deficits that alter learning and memory. Hum Mol Genet 21:3025-3041. CrossRef Medline

McGuire SE, Le PT, Davis RL (2001) The role of Drosophila mushroom body signaling in olfactory memory. Science 293:1330-1333. CrossRef Medline

Murrell J, Farlow M, Ghetti B, Benson MD (1991) A mutation in the amy- 
loid precursor protein associated with hereditary Alzheimer's disease. Science 254:97-99. CrossRef Medline

Nellessen N, Rottschy C, Eickhoff SB, Ketteler ST, Kuhn H, Shah NJ, Schulz JB, Reske M, Reetz K (2015) Specific and disease stage-dependent episodic memory-related brain activation patterns in Alzheimer's disease: a coordinate-based meta-analysis. Brain Struct Funct 220:1555-1571. CrossRef Medline

Peiris H, Dubach D, Jessup CF, Unterweger P, Raghupathi R, Muyderman H, Zanin MP, Mackenzie K, Pritchard MA, Keating DJ (2014) RCAN1 regulates mitochondrial function and increases susceptibility to oxidative stress in mammalian cells. Oxid Med Cell Longev 2014:520316. CrossRef Medline

Perluigi M, Pupo G, Tramutola A, Cini C, Coccia R, Barone E, Head E, Butterfield DA, Di Domenico F (2014) Neuropathological role of PI3K/ Akt/mTOR axis in Down syndrome brain. Biochim Biophys Acta 1842: 1144-1153. CrossRef Medline

Porta S, Serra SA, Huch M, Valverde MA, Llorens F, Estivill X, Arbonés ML, Martí E (2007) RCAN1 (DSCR1) increases neuronal susceptibility to oxidative stress: a potential pathogenic process in neurodegeneration. Hum Mol Genet 16:1039-1050. CrossRef Medline

Rovelet-Lecrux A, Hannequin D, Raux G, Le Meur N, Laquerrière A, Vital A, Dumanchin C, Feuillette S, Brice A, Vercelletto M, Dubas F, Frebourg T, Campion D (2006) APP locus duplication causes autosomal dominant early-onset Alzheimer disease with cerebral amyloid angiopathy. Nat Genet 38:24-26. CrossRef Medline

Sarantseva S, Timoshenko S, Bolshakova O, Karaseva E, Rodin D, Schwarzman AL, Vitek MP (2009) Apolipoprotein E-mimetics inhibit neurodegeneration and restore cognitive functions in a transgenic Drosophila model of Alzheimer's disease. PLoS One 4:e8191. CrossRef Medline

Séjourné J, Plaçais PY, Aso Y, Siwanowicz I, Trannoy S, Thoma V, Tedjakumala SR, Rubin GM, Tchénio P, Ito K, Isabel G, Tanimoto H, Preat T (2011) Mushroom body efferent neurons responsible for aversive olfactory memory retrieval in Drosophila. Nat Neurosci 14:903-910. CrossRef Medline

Shaw JL, Chang KT (2013) Nebula/DSCR1 upregulation delays neurodegeneration and protects against APP-induced axonal transport defects by restoring calcineurin and GSK-3beta signaling. PLoS Genet 9:e1003792. CrossRef Medline

Simón AM, Schiapparelli L, Salazar-Colocho P, Cuadrado-Tejedor M, Escribano L, López de Maturana R, Del Río J, Pérez-Mediavilla A, Frechilla D (2009) Overexpression of wild-type human APP in mice causes cognitive deficits and pathological features unrelated to Abeta levels. Neurobiol Dis 33:369-378. CrossRef Medline

Skoulakis EM, Davis RL (1996) Olfactory learning deficits in mutants for leonardo, a Drosophila gene encoding a 14-3-3 protein. Neuron 17:931944. CrossRef Medline

Skoulakis EM, Kalderon D, Davis RL (1993) Preferential expression in mushroom bodies of the catalytic subunit of protein kinase A and its role in learning and memory. Neuron 11:197-208. CrossRef Medline

Sleegers K, Brouwers N, Gijselinck I, Theuns J, Goossens D, Wauters J, DelFavero J, Cruts M, van Duijn CM, Van Broeckhoven C (2006) APP duplication is sufficient to cause early onset Alzheimer's dementia with cerebral amyloid angiopathy. Brain 129:2977-2983. CrossRef Medline

Sofola O, Kerr F, Rogers I, Killick R, Augustin H, Gandy C, Allen MJ, Hardy J,
Lovestone S, Partridge L (2010) Inhibition of GSK-3 ameliorates Abeta pathology in an adult-onset Drosophila model of Alzheimer's disease. PLoS Genet 6:e1001087. CrossRef Medline

Steffan JS, Bodai L, Pallos J, Poelman M, McCampbell A, Apostol BL, Kazantsev A, Schmidt E, Zhu YZ, Greenwald M, Kurokawa R, Housman DE, Jackson GR, Marsh JL, Thompson LM (2001) Histone deacetylase inhibitors arrest polyglutamine-dependent neurodegeneration in Drosophila. Nature 413:739-743. CrossRef Medline

Sun X, Wu Y, Chen B, Zhang Z, Zhou W, Tong Y, Yuan J, Xia K, Gronemeyer H, Flavell RA, Song W (2011) Regulator of calcineurin 1 (RCAN1) facilitates neuronal apoptosis through caspase-3 activation. J Biol Chem 286:9049-9062. CrossRef Medline

Sun X, Wu Y, Herculano B, Song W (2014) RCAN1 overexpression exacerbates calcium overloading-induced neuronal apoptosis. PLoS One 9:e95471. CrossRef Medline

Tamura T, Chiang AS, Ito N, Liu HP, Horiuchi J, Tully T, Saitoe M (2003) Aging specifically impairs amnesiac-dependent memory in Drosophila. Neuron 40:1003-1011. CrossRef Medline

Tonoki A, Davis RL (2012) Aging impairs intermediate-term behavioral memory by disrupting the dorsal paired medial neuron memory trace. Proc Natl Acad Sci U S A 109:6319-6324. CrossRef Medline

Tully T, Quinn WG (1985) Classical conditioning and retention in normal and mutant Drosophila melanogaster. J Comp Physiol A 157:263-277. CrossRef Medline

Tully T, Preat T, Boynton SC, Del Vecchio M (1994) Genetic dissection of consolidated memory in Drosophila. Cell 79:35-47. CrossRef Medline

Wang M, Gamo NJ, Yang Y, Jin LE, Wang XJ, Laubach M, Mazer JA, Lee D, Arnsten AF (2011) Neuronal basis of age-related working memory decline. Nature 476:210-213. CrossRef Medline

Warrick JM, Paulson HL, Gray-Board GL, Bui QT, Fischbeck KH, Pittman RN, Bonini NM (1998) Expanded polyglutamine protein forms nuclear inclusions and causes neural degeneration in Drosophila. Cell 93:939_ 949. CrossRef Medline

Wu Y, Deng Y, Zhang S, Luo Y, Cai F, Zhang Z, Zhou W, Li T, Song W (2015) Amyloid-beta precursor protein facilitates the regulator of calcineurin 1 -mediated apoptosis by downregulating proteasome subunit alpha type-5 and proteasome subunit beta type-7. Neurobiol Aging 36:169177. CrossRef Medline

Yamazaki D, Horiuchi J, Nakagami Y, Nagano S, Tamura T, Saitoe M (2007) The Drosophila DCO mutation suppresses age-related memory impairment without affecting lifespan. Nat Neurosci 10:478-484. CrossRef Medline

Yang Y, Nishimura I, Imai Y, Takahashi R, Lu B (2003) Parkin suppresses dopaminergic neuron-selective neurotoxicity induced by Pael-R in Drosophila. Neuron 37:911-924. CrossRef Medline

Yin JC, Wallach JS, Del Vecchio M, Wilder EL, Zhou H, Quinn WG, Tully T (1994) Induction of a dominant negative CREB transgene specifically blocks long-term memory in Drosophila. Cell 79:49-58. CrossRef Medline

Zeng H, Chattarji S, Barbarosie M, Rondi-Reig L, Philpot BD, Miyakawa T, Bear MF, Tonegawa S (2001) Forebrain-specific calcineurin knockout selectively impairs bidirectional synaptic plasticity and working/episodiclike memory. Cell 107:617-629. CrossRef Medline 